\begin{tabular}{|c|c|c|}
\hline UNNFS & $\begin{array}{l}\text { Jurnal Fisika } 10 \text { (2) (2020) 11-18 } \\
\text { Jurnal Fisika } \\
\text { https://journal.unnes.ac.id/nju/index.php/jf/index }\end{array}$ & Jurnal Fisika \\
\hline & & \\
\hline
\end{tabular}

\title{
Analisis Pengaruh Konsentrasi Natrium Hidroksida terhadap Sifat Mekanik Biokomposit Berpenguat Serat Sisal
}

\author{
Amirin Kusmiran $^{1 凶}$, Noval Suwandi ${ }^{2}$ dan Rita Desiasni ${ }^{2}$ \\ ${ }^{1}$ Jurusan Fisika, Fakultas Sains dan Teknologi, UIN Alauddin Makassar, Romangpolong, Gowa, 92111 \\ ${ }^{2}$ Program Studi Teknik Metalurgi, Fakultas Teknik, Universitas Teknologi Sumbawa, Batu Alang, \\ Sumbawa, 84371
}

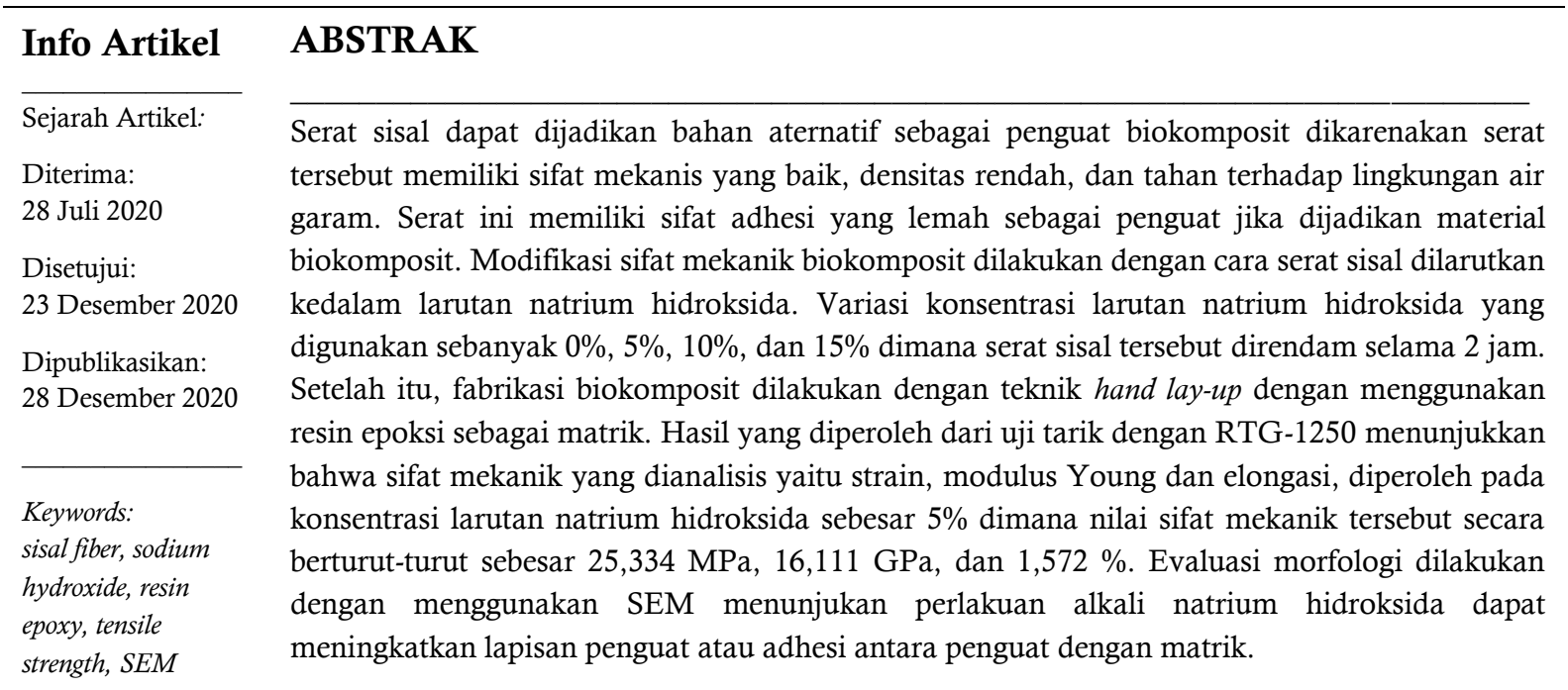

\section{ABSTRACT}

The sisal fibre has used as alternative material as fiber of bio-composite because the sisal fiber has good mechanical properties, low density, and resistant to the saltwater environment. These fibers have poor interfacial adhesion properties as the fibers if used as bio-composite material. This problem can be solved by the surface modification method by the sodium hydroxide treatment used to improve the mechanical properties. A sodium hydroxide concentration which it used at $0 w t \%, 5 w t \%, 10 w t \%$, and $15 w t \%$ and the sisal fibers were soaked in that a concentration for 2 hours. Furthermore, the bio-composite fabrication is conducted by hand lay-up technique which is using both sisals as the fibers and epoxy resin as the matrix. The tensile test RTG-1250 results show that the maximum mechanical properties, such as strains, Young's modulus, and elongation, was obtained at sodium hydroxide $5 w t \%$ than others where the values of these mechanical properties were $25.334 \mathrm{MPa}, 16.111 \mathrm{GPa}$, and $1.572 \%$, respectively. The morphological evaluation carried out using SEM showed that the alkali sodium hydroxide treatment was improved interfacial adhesion between fiber and matrix.

(C) 2020 Universitas Negeri Semarang

\footnotetext{
Alamat korespondensi:

Jurusan Fisika, Fakultas Sains dan Teknologi, UIN Alauddin Makassar

E-mail: amirin19@gmail.com
} 


\section{PENDAHULUAN}

Pengembangan pemanfaatan bahan alami yang dapat diperbaharui, seperti serat sisal, serat nanas, serat bamboo, dan lain sebagainya untuk pembuatan material komposit terus dikembangkan sebagai bahan pengganti serat sintetik seperti glass fibers (Barreto dkk., 2010; Mittal dkk., 2016). Disamping dapat diperbaharui, bahan alami ini juga mempunyai manfaat lain yakni tidak terkorosi, bobot ringat, ramah lingkungan, dan harga murah. Salah satu bahan alami yang dapat digunakan untuk pembuatan material komposit yakni serat sisal. Serat sisal dapat diaplikasikan pada bidang kerajinan, kesehatan, dan industri secara berurutan seperti pembuatan tali, bahan alternatif penguat basis gigi tiruan, dan bahan pembuatan produk polimer. Selain itu, serat sisal memiliki daya keuletan yang lebih tinggi, densitas rendah dibandingkan serat flax, jute dan katun, dan dapat diaplikasikan pada lingkungan kadar garam yang tinggi (Hulle dkk., 2015; Joseph dkk., 1999).

Sifat mekanik yang dihasilkan pada pembuatan komposit dengan serat alami termasuk serat sisal dapat dipengaruhi oleh kualitas serat, dan permukaan antara penguat dengan matriks (Senthilkumar dkk., 2018). Sifat permukaan serat tersebut dipengaruhi oleh selulosa, hemiselulosa, lignin, pectin, wax, dan senyawa yang larut dalam air dengan persentase komposisi secara berturutturut sebesar $65,8 \%, 12 \%, 9,9 \%, 0,8 \%, 0,3 \%$, dan sisanya (Barreto dkk., 2011). Namun, penggunaan serat sisal sebagai penguat pada pembuatan komposit kurang memberikan efek yang maksimal dikarenakan oleh sifat hidrofilik dari serat yang mengandung gugus polar hidroksil yang tinggi sehingga dapat membuat adhesi permukaan serat alami dengan resin polimer menjadi rendah dan mudah terdegradasi.

Modifikasi sifat mekanik biokomposit dapat dilakukan dengan pengaturan arah serat (Kusmiran dkk., 2019) maupun secara kimia. Perlakuan kimia ini dilakukan dengan cara perlakuan alkali seperti $\mathrm{NaOH}$ dan $\mathrm{KOH}$ terlebih dahulu sebelum digunakan sebagai bahan penguat dari suatu material (Barreto dkk., 2011; Boopathi dkk., 2012; T.P. Mohan, 2012). Hal ini dilakukan dengan tujuan agar dapat meningkatkan adhesi serat dengan matrik, mengurangi kandungan air dari serat dan meningkatkan sifat mekanik biokomposit berpenguat serat alami.

Natrium hidroksida merupakan salah satu senyawa kimia yang bersifat alkali/basa dan berfungsi untuk menghilangkan atau membersihkan zat-zat dan kotoran-kotoran yang melekat pada serat sisal. Disamping itu, alkali natrium hidroksida dapat memodifikasi bentuk kristal dari penguat sehingga dapat mereduksi sifat hidrofilik dan meningkatkan kristalisasi fiber sehingga dapat mengoptimalkan adhesi serat dengan matriks (Alshammari dkk., 2019; Nam dkk., 2011). Waktu perendaman alkali natrium hidroksida juga dapat meningkatkan sifat mekanik serat dan mempengaruhi komposisi kimia pada serat buah lontar (Reddy dkk., 2013). Selain itu, investigasi variasi konsentrasi $1 \%$ sampai $10 \%$ natrium hidroksida pada serat kurma dapat memberikan pengaruh terhadap sifat thermal dan morfologi serat sebagaimana dilakukan oleh Oushabi dkk. (2017). Selain itu juga, alkali natrium hidroksida dapat memberikan dampak signifikan pada sifat mekanik fly ash pada pembuatan geopolimer (Hamidi dkk., 2016).

Evaluasi sifat mekanik biokomposit, khususnya serat sisal, yang dilakukan dengan variasi konsentrasi dari larutan natrium hidroksida $(\mathrm{NaOH})$ menjadi fokus pada penelitian ini. Perbandingan penguat dengan matriks yakni $15 \%$ penguat dengan $85 \%$ matriks pada pembuatan biokomposit. Evaluasi sifat mekanik dilakukan dengan uji tarik pada biokomposit tanpa perlakuan $\mathrm{NaOH}$, dan perlakuan konsentrasi $\mathrm{NaOH} \mathrm{5 \% ,10 \%} \mathrm{dan} \mathrm{15 \% .} \mathrm{Morfologi} \mathrm{dari} \mathrm{biokomposit} \mathrm{berpenguat} \mathrm{serat} \mathrm{sisal}$ dievaluasi dengan menggunakan scanning electron microscope (SEM).

\section{METODE}

\section{Preparasi Sampel}

Penelitian ini menggunakan serat sisal serat sisal yang diperoleh dari petani lokal Kab. Sumbawa Barat-NTB. Serat sisal tersebut dicuci dengan air bersih untuk menghilangkan kotoran- 
kotoran yang menempel pada permukaan, dan dikeringkan secara alami untuk menghilangkan kadar air dari serat sisal. Serat sisal tersebut direndam ke dalam larutan $\mathrm{NaOH}$ analitik dengan variasi $\mathrm{NaOH}$ sebesar $5 \%, 10 \%$, dan $15 \%$ selama 2 jam. Serat sisal yang telah direndam dengan larutan $\mathrm{NaOH}$ kemudian dibilas dengan air sampai bersih dan kemudian dikeringkan. Campuran serat sisal dengan resin epoksi ke dalam cetakan seperti pada Gambar 1 dengan menggunakan metode hand layup.

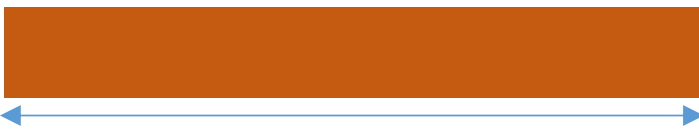

panjang 250

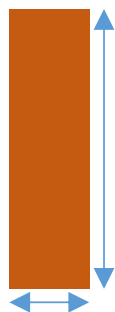

tinggi $3 \mathrm{~mm}$

lebar $25 \mathrm{~mm}$

Gambar 1. Dimensi benda uji tarik komposit ASTM D 3039.

Dimensi cetakan sampel biokomposit diperlihatkan pada Gambar 1 dengan panjang $250 \mathrm{~mm}$, lebar $25 \mathrm{~mm}$, dan tinggi $3 \mathrm{~mm}$. Perbandingan volume yang digunakan antara serat sisal dengan resin epoksi yakni $15 \%$ serat sisal dan $85 \%$ resin epoksi. Biokomposit berpenguat serat sisal yang telah dicetak selanjutnya dimasukan ke dalam oven dengan suhu $100^{\circ} \mathrm{C}$ selama 3 jam untuk proses post curing. Tujuannya untuk menghilangkan gelembung udara dan uap air yang terperangkap pada biokomposit.

\section{Pengujian sifat mekanik dan morfologi}

Sifat mekanik biokomposit diketahui dengan melakukan uji tarik pada setiap sampel komposit bertujuan untuk mengetahui besarnya kekuatan tarik dari spesimen biokomposit dengan menggunakan mesin uji RTG-1250. Pengujian tarik dilakukan untuk biokomposit tanpa perlakuan $\mathrm{NaOH}$, dan perlakuan konsentrasi $\mathrm{NaOH} 5 \%, 10 \%$ dan $15 \%$. Selain uji tarik, pengamatan morfologi permukaan dilakukan menggunakan alat Scanning Electron Microscope (SEM) untuk mengetahui morfologi permukaan serat sisal sebelum dan setelah perlakuan $\mathrm{NaOH}$.

\section{HASIL DAN PEMBAHASAN}

\section{Sifat Mekanik komposit serat sisal-epoksi}

Sampel uji biokomposit berpenguat serat sisal diperlihatkan pada Gambar 2 dimana sampel tersebut menggunakan serat sisal sebagai penguat dan resin epoksi sebagai matrik.

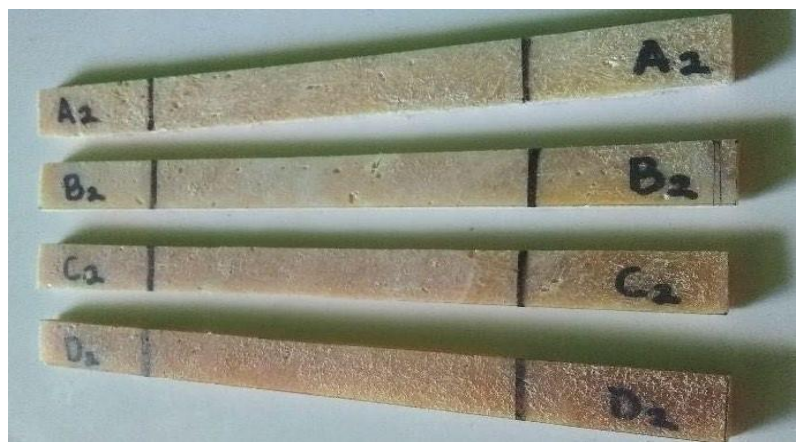

Gambar 2. Sampel uji tarik biokomposit (a) $\mathrm{A}_{2}$ tanpa perlakuan $\mathrm{NaOH}$ (b) $\mathrm{B}_{2}$ perlakuan $5 \%$ $\mathrm{NaOH}$; (c) $\mathrm{C}_{2}$ perlakuan $10 \% \mathrm{NaOH}$ (d) $\mathrm{D}_{2}$ perlakuan $15 \% \mathrm{NaOH}$.

Pengujian sifat mekanik material biokomposit telah dilakukan dengan menggunakan mesin uji Tarik RTG-1250 dengan hasil pengujian diperlihatkan pada Gambar 3. 

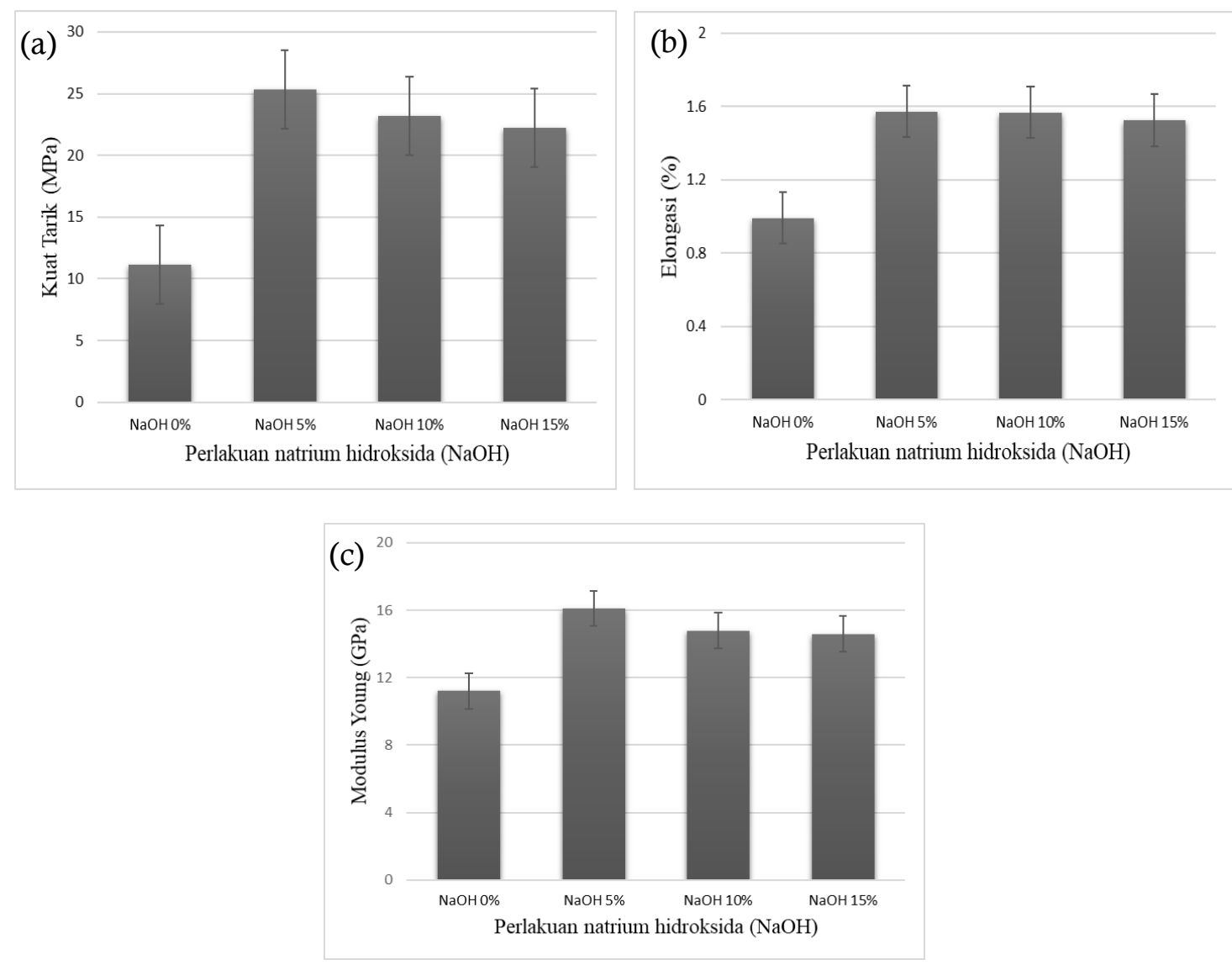

Gambar 3. Hasil pengujian sifat mekanik biokomposit berpenguat serat sisal (a). Kuat Tarik (MPa), (b) Elongasi (\%), (c) Modulus Young (GPa)

Nilai kuat tarik tertinggi sebesar $25.3340 \mathrm{MPa}$. Nilai tersebut diperoleh pada biokomposit dengan perlakuan penambahan konsentrasi $\mathrm{NaOH}$ sebesar 5\%. Gambar 3a menunjukan bahwa konsentrasi $\mathrm{NaOH}$ sebesar 5\% mempunyai kekuatan tarik optimum dibandingkan dengan tanpa perlakuan $\mathrm{NaOH}$, konsentrasi $\mathrm{NaOH} 10 \%$, dan konsentrasi $\mathrm{NaOH}$ 15\% dimana nilai kekutan tarik tersebut sebesar $25.3340(\mathrm{MPa})$. Hal ini menunjukkan bahwa sifat mekanik biokomposit berpenguat serat sisal dapat ditingkatkan dengan penambahan konsentrasi $\mathrm{NaOH}$ sebesar $5 \%$ selama 2 jam. Selain itu, Gambar 3a juga menunjukan tanpa perlakuan $\mathrm{NaOH}$ mempunyai kekuatan tarik yang terkecil sebesar $11.1136 \mathrm{MPa}$, jika dibandingkan dengan perlakuan konsentrasi $\mathrm{NaOH} 5 \%, 10 \%$, dan $15 \%$. Ini menunjukan bahwa tanpa perlakuan $\mathrm{NaOH}$ dapat menyebabkan ikatan antar serat dan resin menjadi tidak sempurna karena terhalang lapisan yang menyerupai lilin di permukaan serat (Venkateshwaran dkk., 2013).

Persentase elongasi biokomposit berpenguat serat sisal tanpa perlakuan $\mathrm{NaOH}$ sebesar 0.9924 $\%$ dimana elongasi ini merupakan referensi dari persentasi konsentrasi dengan perlakuan alkali natrium hidroksida. Biokomposit berpenguat serat sisal dengan perlakuan $\mathrm{NaOH}$ konsentrasi $5 \%$, $10 \%$ dan $15 \%$ berurutan $1.5725 \%, 1.5677 \%$ dan $1.5249 \%$. Hasil ini menunjukkan bahwa nilai elastisitas biokomposit berpenguat serat dapat dimodifikasi dengan perlakuan $\mathrm{NaOH}$ sebagaimana diperlihatkan oleh Gambar 3b. Namun, konsentrasi NaOH lebih dari 5\% menyebabkan penurunan nilai elastisitas atau regangan biokomposit berpenguat serat sisal. Hal ini sesuai dengan penelitian pada serat alami yakni serat bamboo dan serat kurma (Oushabi dkk., 2017; Wong dkk., 2010).

Sifat mekanik berupa Modulus Young pada Gambar 3c memiliki nilai optimum pada konsentrasi $\mathrm{NaOH}$ sebesar 5\% sedangkan di atas konsentrasi tersebut nilai modulus Young semakin berkurang secara gradual. Nilai optimum tersebut dikarenakan larutan $\mathrm{NaOH}$ dapat mengurangi lapisan lemah seperti lilin, hemiselulosa, lignin, lemak dan kotoran lainnya pada permukaan serat 
yang dapat menghalangi ikatan antara serat dan matriks (Hamidi dkk., 2016; Oushabi dkk., 2017). Konsentrasi $\mathrm{NaOH}$ lebih dari 5\% mengakibatkan serat mengalami degradasi dan akhirnya rapuh dikarenakan penambahan konsentrasi $\mathrm{NaOH}$ diatas 5\% dapat mengakibatkan lapisan seral sisal mengalami pengikisan. Dengan demikian kuat tarik dan modulus Young mengalami penurunan sifat mekanis. Hal ini menunjukan bahwa konsentrasi kadar $\mathrm{NaOH}$ saat perlakuan alkali memiliki efek yang cukup besar terhadap kompatibilitas serat (Yudhanto dkk., 2016).

Besarnya persantase peningkatan sifat mekanik biokomposit yang diakibatkan oleh perlakuan natrium hidroksida dapat dihitung dengan menggunakan persamaan \% peningkatan (Reddy dkk., 2013).

$$
\% \text { Peningkatan }=\frac{\text { kuat tarik perlakuan-kuat tarik tanpa perlakuan }}{\text { kuat tarik perlakuan }} \times 100 \%
$$

Berdasarkan persamaan tersebut, besar \% peningkatan sifat mekanik akibat dari perlakuan natrium hidroksida jika dibandingkan dengan tanpa perlakuan (UT) diperlihatkan pada Tabel 1.

Tabel 1. Persentase peningkatan sifat mekanik biokomposit.

\begin{tabular}{cccc}
\hline Variasi & \multicolumn{3}{c}{ Sifat mekanik } \\
\cline { 2 - 4 } $\mathrm{NaOH} \%$ & Kekuatan/strength (\%) & Modulus Young (\%) & Elongasi (\%) \\
\hline $0 / \mathrm{UT}$ & - & - & - \\
\hline 5 & 56,13 & 30,49 & 36,89 \\
\hline 10 & 47,68 & 22,32 & 36,59 \\
\hline 15 & 43,94 & 21,04 & 33,86 \\
\hline
\end{tabular}

Jika dibandingkan dengan tanpa perlakuan (UT), serat sisal dengan perlakuan alkali natrium hidroksida $(\mathrm{NaOH})$ mengalami peningkatan sifat mekanik optimal seperti strength, modulus Young, dan $\%$ elongasi secara berurutan sebesar 56,13\%, 30,49\%, dan 36,89\% yang berada pada konsentrasi $5 \%$ alkali natrium hidroksida.

\section{Hasil Scanning Electron Microscope}

Sifat fisis atau mekanik dari biokomposit berpenguat serat sisal dapat dipengaruhi oleh perlakuan alkali $\mathrm{NaOH}$ dapat dilihat dari morfologi biokomposit berpenguat serat sisal seperti yang diperlihatkan pada Gambar 4. 

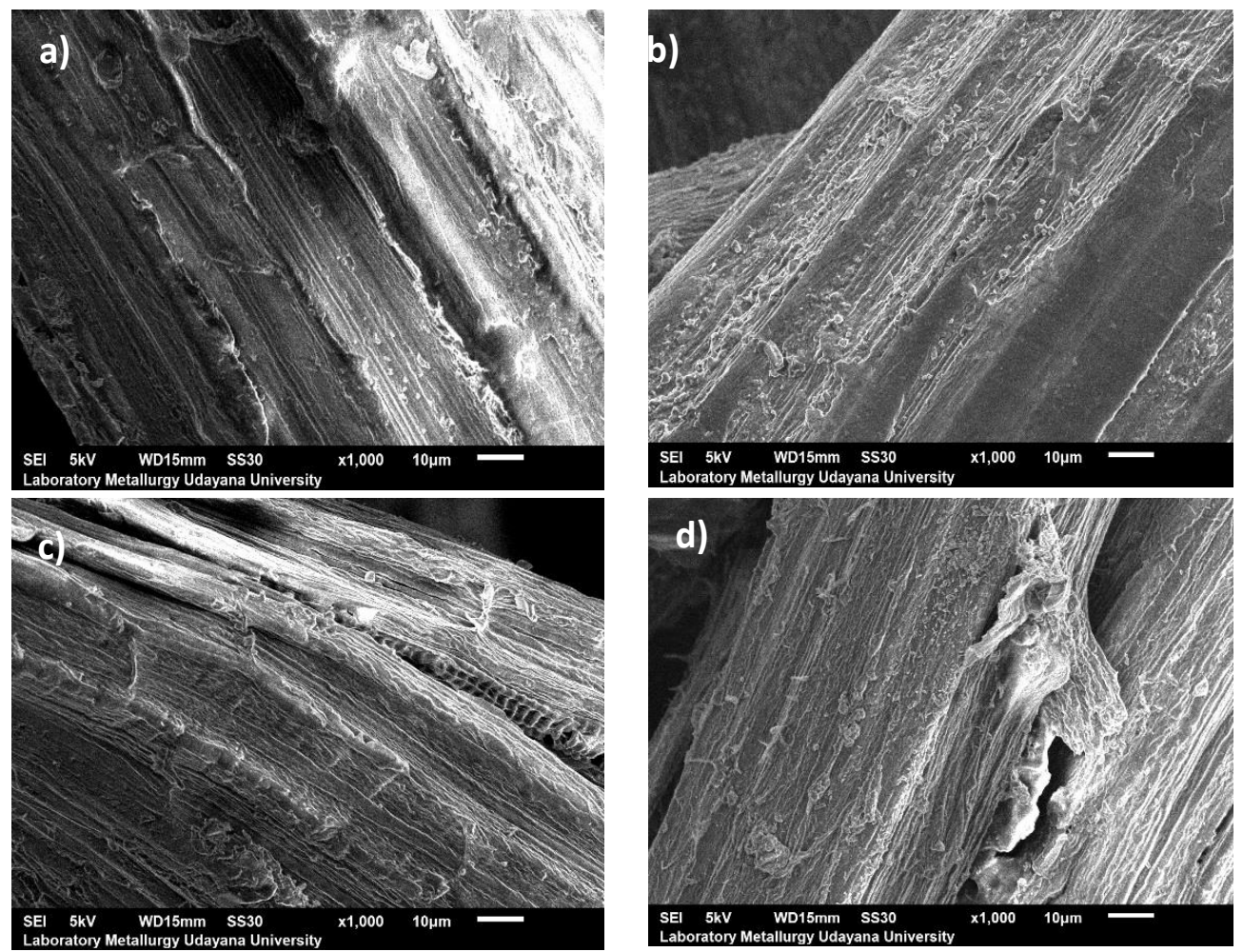

Gambar 4. Morfologi permukaan serat sisal dengan perlakuan \% NaOH. (a) Tanpa Perlakuan; (b) $5 \% \mathrm{NaOH}$; (c) $10 \% \mathrm{NaOH}$ (d) $15 \% \mathrm{NaOH}$.

Gambar 4 menunjukkan morfologi serat sisal dengan perlakuan variasi konsentrasi alkali natrium hidroksida dimana alkali tersebut dapat mepengaruhi morfologi atau kualitas permukaan serat sisal. Serat sisal tersebut dilakukan tanpa dan dengan perlakuan alkali natrium hidroksida selama 2 jam. Perendaman alkali tersebut dapat membuat penyusun non-selulosa seperti hemiselulosa, lignin, dan pektin dari permukaan serat sehingga adhesi antara serat sisal dan matrik (resin epoksi) meningkat (Deng dkk., 2013; Orue dkk., 2015). Peningkatan adhesi permukaan ini dapat meningkatkan sifat mekanik biokomposit jika dibandingkan dengan raw material sebagaimana yang diperlihatkan pada Tabel 1. Peningkatan sifat mekanik ini mengindikasikan bahwa perlakuan alkali natrium hidroksida menyebabkan menghilangnya lapisan amorf sehingga dapat meningkatkan modulus Young (Oushabi dkk., 2017).

Dari pengamatan morfologi permukaan serat sisal melalui foto SEM tanpa perlakuan $\mathrm{NaOH}$ menggunakan perbesaran 1000 kali dengan skala $100 \mu \mathrm{m}$, serat sisal tanpa perlakuan (Gambar 4 (a)) menunjukan lapisan lilin yang menyebabkan adhesi permukaan penguat dengan penguat kurang bagus sehingga sifat mekaniknya terkecil daripada yang mengalami perlakuan alkali sebagaimana diperlihatkan pada Gambar 3. Hal yang sebaliknya terlihat pada (Gambar 4 (b), (c) dan (d)) menunjukan serat yang sudah mengalami proses perendaman $\mathrm{NaOH}$ memiliki permukaan yang bersih dari pengotor seperti yang terlihat pada Gambar 4. Selain itu, penambahan konsentrasi alkali natrium hidroksida membuat terjadinya penurunan sifat mekanik material dikarenakan terjadinya pengikisan pada lapisan serat. Dengan demikian struktur serat mengalami kerusakan (struktur hemiselulosa dan selulosa) berupa adanya retakan pada serat sebagaimana diperlihatkan pada Gambar 4b dan 4c. Selain itu, perendaman serat sisal dengan alkali natrium hidroksida dapat mengurangi ukuran diameter dari serat tersebut (Arsyad dkk., 2017). Serat sisal mempunyai sifat kuat tarik yang lebih tinggi dibandingkan dengan serat rami, kenaf, pisang, dan tebu sebagaimana diungkapkan oleh Mohammed dkk. (2015). 


\section{SIMPULAN}

Peningkatkan sifat mekanik biokomposit telah berhasil dilakukan dengan pelakuan pemberian konsentrasi larutan alkali natrium hidroksida sebesar 5\%, 10\%, dan $15 \%$ pada serat sisal selama 2 jam. Sifat mekanik yang dianalisis yaitu strain, modulus Young, dan elongasi optimal diperoleh secara berturut-turut sebesar 25, $334 \mathrm{MPa}, 16,111 \mathrm{GPa}$, dan 1,572\%. Nilai maksimum ini diperoleh pada perlakuan alkali natrium hidroksida sebesar $5 \%$ pada serat sisal. Hasil tersebut disebabkan oleh larutan alkali natrium hidroksida dapat menghilangkan bagian amorphous pada serat sisal sehingga dapat memperkuat adhesi antara penguat serat sisal dengan matrik resin epoksi. Hal ini dapat dilihat dari morfologi serat sisal yang diperoleh dari SEM dimana permukaan serat sisal lebih rata tanpa adanya retakan jika dibandingkan dengan tanpa perlakuan alkali natrium hidroksida maupun adanya perlakukan natrium hidroksida pada konsentrasi larutan sebesar 10\% dan 15\%. Dengan demikian, perlakuan alkali $\mathrm{NaOH}$ dapat mempengaruhi sifat mekanik biokomposit berpenguat serat sisal dimana sifat mekanik optimal pada konsentrasi $\mathrm{NaOH} 5 \%$, dan penambahan konsentrasi $\mathrm{NaOH}$ diatas 5\% dapat menurunkan sifat mekanik biokomposit berpenguat serat sisal. Penurunan sifat mekanik tersebut dikarenakan pengikikisan lapisan serat sisal pada selulosa dan hemiselulosa.

\section{REFERENSI}

Alshammari, B. A., Saba, N., Alotaibi, M. D., Alotibi, M. F., Jawaid, M., \& Alothman, O. Y. (2019). Evaluation of Mechanical, Physical, and Morphological Properties of Epoxy Composites Reinforced with Diferent Date Palm Fillers. Materials, 12(2145), 1-17.

Arsyad, M., \& Salam, A. (2017). Analisis Pengaruh Konsentrasi Larutan Alkali Terhadap Perubahan Diameter Serat Sabut Kelapa. Journal INTEK, 4(1), 10-13.

Barreto, A. C. H., Esmeraldo, M. A., D.S. Rosa, P. B. A. F., \& Mazzetto, S. E. (2010). Cardanol Biocomposites Reinforced with Jute Fiber: Microstructure, Biodegradability, and Mechanical Properties. POLYMER COMPOSITES, 31(11), 1928-1937.

Barreto, A. C. H., Rosa, D. S., Fechine, P. B. A., \& Mazzetto, S. E. (2011). Properties of sisal fibers treated by alkali solution and their application into cardanol-based biocomposites. Composites: Part A, 42, 492-500.

Boopathi, L., Sampath, P. S., \& Mylsamy, K. (2012). Investigation of physical, chemical and mechanical properties of raw and alkali treated Borassus fruit fiber. Composites: Part B, 43, 30443052.

Deng, Y., Liu, H., \& Yu, W. (2013). The Effect of Chemical Treatment on Sisal Fiber Property. Advanced Materials Research, 821-822, 72-75.

Hamidi, R. M., Man, Z., \& Azizli, K. A. (2016). Concentration of $\mathrm{NaOH}$ and the Effect on the Properties of Fly Ash Based Geopolymer. Procedia Engineering, 148, 189-193.

Hulle, A., Kadole, P., \& Katkar, P. (2015). Agave Americana Leaf Fibers. Fibers, 3, 64-75. Kusmiran, A., Hidayat, M., Desiasni, R., \& Maad, A. Z. (2019). Numerical analysis of Composite with Natural Fiber Reinforcement using Finite Element Method: Leaf Spring Composite Application Paper presented at the ICOST, Makassar.

Mittal, V., Saini, R., \& Sinha, S. (2016). Natural fiber-mediated epoxy composites -A review. Composites Part B, 99, 425-435.

Mohammed, L., Ansari, M.N.M., Pua, G., Jawaid, M., \& Islam, M.S. (2015). A review on natural fiber reinforced polymer composite and its application. International Journal on Polymer Science, Volume 2015, 1-15.

Nam, T. H., Ogihara, S., Tung, N. H., \& Kobayashi, S. (2011). Effect of alkali treatment on interfacial and mechanical properties of coir fiber reinforced poly(butylene succinate) biodegradable composites. Composites: Part B, 42, 1648-1656.

Orue, A., Jauregi, A., Peña-Rodriguez, C., Labidi, J., Eceiza, A., \& Arbelaiz, A. (2015). The effect of surface modifications on sisal fiber properties and sisal/poly (lactic acid) interface adhesion. Composites: Part $B, x x x, 1-7$.

Oushabi, A., Sair, S., Hassani, F. O., Abboud, Y., Tanane, O., \& Bouari, A. E. (2017). The effect of alkali treatment on mechanical,morphological and thermal properties of date palm fibers (DPFs): Study of the interface of DPF-Polyurethane composite. South African Journal of Chemical 
Engineering, 23, 116-123.

Joseph, K., Filho, R.D.T., James, B., Thomas, S., \& Carvalho, L.H. (1999). A Review on sisal fiber reinforced polymer composites. Revista Brasileira de Engenharia Agricola e Ambiental, 3, 367-379.

Reddy, K. O., Maheswari, C. U., Shukla, M., Song, J. I., \& Rajulu, A. V. (2013). Tensile and structural characterization of alkali treated Borassus fruit fine fibers. Composites: Part B, 44, 433438.

Senthilkumar, K., Saba, N., Rajini, N., Chandrasekar, M., Jawaid, M., Siengchin, S., \& Alotman,

O. Y. (2018). Mechanical properties evaluation of sisal fibre reinforced polymer composites: A review. Construction and Building Materials, 174, 713-729.

T.P. Mohan, K. K. (2012). Chemical treatment of sisal fiber using alkali and clay method. Composites: Part A, 43, 1989-1998.

Venkateshwaran, N., Perumal, A. E., \& Arunsundaranayagam, D. (2013). Fiber surface treatment and its effect on mechanical and visco-elastic behaviour of banana/epoxy composite. Materials and Design, $47,151-159$

Wong, K. J., Yousif, B. F., \& Low, K. O. (2010). The effects of alkali treatment on the interfacial adhesion of bamboo fibres. J. Materials: Design and Applications, 224, 139- 147.

Yudhanto, F., Wisnujati, A., \& Kusmono. (2016). Pengaruh Perlakuan Alkali Terhadap Kekuatan Tarik dan Wettability Serat Alam Agave Sisalana Perrine. Paper presented at the Seminar Nasional XI "Rekayasa Teknologi Industri dan Informasi", Yogyakarta. 